\title{
Pb-210 sediment chronology: Focused on supported lead*
}

\author{
D. Pittauerová, B. Hettwig and H.W. Fischer \\ Institute of Environmental Physics, University of Bremen, 28334 Bremen, Germany
}

\begin{abstract}
A widely applied method of supported lead estimation in sediments using gamma spectrometric ${ }^{226} \mathrm{Ra}$ determination via ${ }^{222} \mathrm{Rn}$ short lived daughter products relies on radioactive equilibrium between ${ }^{226} \mathrm{Ra}$ and ${ }^{222} \mathrm{Rn}$ being established after sealing the samples. Advantages and disadvantages of methods of ${ }^{226} \mathrm{Ra}$ estimation in sediments, using either ${ }^{226} \mathrm{Ra}$ daughter products or direct estimation by the $186.2 \mathrm{keV}$ gammaemissions are discussed. An equilibrium experiment was performed using test samples and in one case radioactive equilibrium was not reached. On theoretical sediment profiles it is shown how systematic errors in supported ${ }^{210} \mathrm{~Pb}$ estimation can lead to wrong interpretations of ${ }^{210} \mathrm{~Pb}$ xs profiles and therefore affect ${ }^{210} \mathrm{~Pb}$ derived chronologies.
\end{abstract}

\section{INTRODUCTION}

${ }^{210} \mathrm{~Pb}$ sediment chronology is a frequently used tool for dating recent lacustrine and marine sediment cores or peat bog accumulations [1]. Its range is approximately the last 100-150 years, which is the period of the most significant anthropogenic effects to the environment. ${ }^{210} \mathrm{~Pb}$ (half-life 22.3 years) in sediments consists of two components:

- supported ${ }^{210} \mathrm{~Pb}$, which is present due to autigenic material of the sediment and

○ unsupported (or excess) ${ }^{210} \mathrm{~Pb}$, which originates from the atmospheric deposition.

Excess ${ }^{210} \mathrm{~Pb}$ is then determined by subtracting supported activity from the total activity and used for estimation of accumulation rates and age models. Measurement techniques of total signal of ${ }^{210} \mathrm{~Pb}$ include either alpha spectroscopy via ${ }^{210} \mathrm{Po}$ with assumption of radioactive equilibrium between ${ }^{210} \mathrm{Po}$ and ${ }^{210} \mathrm{~Pb}$, or gamma spectroscopy. Both approaches have certain advantages and disadvantages [2]. In the authors' laboratory, gamma spectroscopy is used. That allows simultaneous estimation of other natural and artificial gamma emitters within a single spectrum and the analysis is non-destructive.

\section{SUPPORTED ${ }^{210}$ PB ESTIMATION}

For supported ${ }^{210} \mathrm{~Pb}$, which is usually assumed to be in radioactive equilibrium with its parent nuclide ${ }^{226} \mathrm{Ra}$ (half-life $1600 \mathrm{yr}$ ), analytical options were suggested by Moser [3]. The simplest method, sometimes used in combination with alpha spectroscopic determination of ${ }^{210} \mathrm{~Pb}$, is to use the lowest constant activity of a sediment profile (samples with an age greater than 100 years). This method assumes a constant activity of ${ }^{226} \mathrm{Ra}$ over the entire sediment profile, which is not always the case. It is also possible to measure Ra by alpha counting or liquid scintillation after radiochemical separation, or gamma spectroscopy [3, 4].

\footnotetext{
*A paper of a similar content was presented at the International Symposium on Isotopes in Hydrology, Marine Ecosystems, and Climate Change Studies held on 27 March - 1 April 2011 in Monaco as: Pittauerová D., Hettwig B. and Fischer H.W.: Supported lead in $\mathrm{Pb}-210$ chronology.
} 


\subsection{Using ${ }^{226}$ Ra daughter products}

Gamma spectroscopy of daughter products of ${ }^{226} \mathrm{Ra}$, namely short lived ${ }^{214} \mathrm{~Pb}$ and ${ }^{214} \mathrm{Bi}$ (further on named "daughter products"), is a widely used method for ${ }^{226} \mathrm{Ra}$ determination. Here we have to deal mainly with difficulties related to ${ }^{222} \mathrm{Rn}$ diffusion and recoil emanations from the sample, leading to systematic underestimation of ${ }^{226} \mathrm{Ra}$ concentration [5]. In the study of Stoulos et al. [6] Rn gas leaking from the sample container, its accumulation in the void upper part of the container and attachment of Rn decay products onto its inner surface, resulting in another geometry, and self-absorption from that of the calibration sample, was resolved by adding active charcoal to the sample. However, this would change properties of the samples, which contradicts one major advantage of gamma spectroscopy for sediment chronology being a non-destructive method. An optional solution is using Rn proof steel containers [6], which would lead to decline in sensitivity in detection of low energy gamma radiation of ${ }^{210} \mathrm{~Pb}$. A common practice in many gamma spectroscopic laboratories is sealing samples using gas-tight foil and waiting for at least 21 days to allow ingrowth of daughter products.

\subsection{Direct estimation}

${ }^{226} \mathrm{Ra}$ can also be directly estimated by its gamma line at $186.2 \mathrm{keV}$, but interference with the most prominent line of ${ }^{235} \mathrm{U} 185.7 \mathrm{keV}$ comes into account. A method for correction of the ${ }^{235} \mathrm{U}$ and ${ }^{226} \mathrm{Ra}$ interference using the $63.3 \mathrm{keV}$ line of ${ }^{234} \mathrm{Th}$ as a proxy for ${ }^{238} \mathrm{U}$ was proposed by Dowdall et al. [7]. In this case constant natural ratio to ${ }^{235} \mathrm{U}$ is assumed. When using the $92.6 \mathrm{keV}$ doublet of ${ }^{234} \mathrm{Th}$, precautions must be taken due to its potential interference with $\mathrm{K}_{\alpha 1}$ line from ${ }^{232} \mathrm{Th}$. Contribution of ${ }^{235} \mathrm{U}$ in the $186 \mathrm{keV}$ peak can also be determined using another less intensive ${ }^{235} \mathrm{U}$ line at $143.8 \mathrm{keV}[8]$, if detectable.

\subsection{Possible ${ }^{226}$ Ra underestimation}

Motivation of this study was the participation of the laboratory in a laboratory intercomparison. It resulted in recognition of the possibility of underestimating ${ }^{226} \mathrm{Ra}$ values. It indicated that the existing laboratory practice of estimation of ${ }^{226} \mathrm{Ra}$ via daughter products using plastic sample dishes sealed in assumed gas-proof metallic foil, was possibly a weak point. As a countermeasure, the laboratory adopted new thicker metallized plastic foil-bags for sealing samples and performed an experiment using soldered steel containers.

\section{MATERIALS AND METHODS}

\subsection{Test samples}

The test sample, denominated RV VII-2006, was a soil material used for the 7th Intercomparison of environmental samples organized by the German Federal office for Radiation Protection (BfS) [5]. It was taken from an area in federal state of Thuringia with naturally increased ${ }^{226} \mathrm{Ra}$ levels. The test material had been grounded into a fine powder, so that $98.8 \%$ of the fraction had a particle size less than $315 \mu \mathrm{m}$. A cylindrical plastic dish with diameter of $70 \mathrm{~mm}$ and height of $20 \mathrm{~mm}$ was filled with the test sample. It was then sealed in a metallized plastic foil, considered to be gas-tight. Another experiment was performed using a steel container with diameter of $101.5 \mathrm{~mm}$ and height of $31.5 \mathrm{~mm}$ in which the test sample was soldered.

\subsection{Gamma spectroscopy}

The samples were measured by low-level low-background gamma spectroscopy using a coaxial HPGe detector Canberra Industries (51\% rel. efficiency) housed in a $10 \mathrm{~cm} \mathrm{~Pb}$ shielding with $\mathrm{Cu}, \mathrm{Cd}$ and 
plastic lining. The spectra were analyzed by Canberra Genie 2000 software. Efficiency calibration was performed using the Monte Carlo based LabSOCS calibration tool [9], which takes into account not only sample to detector geometry, but also sample density and composition, as well as measurement container properties.

\section{EXPERIMENTAL, RESULTS AND DISCUSSION}

\subsection{Equilibrium test}

Gamma spectra of the BfS test samples sealed in 2 upper mentioned ways were recorded repeatedly during approximately 8 weeks $\left(16{ }^{222} \mathrm{Rn}\right.$ half-lives) following their sealing in order to observe the process of radioactive equilibrium establishing. The daughter product ${ }^{214} \mathrm{~Pb}$ was measured via its 242.0, $295.2 \mathrm{keV}$ and $351.9 \mathrm{keV}$ gamma lines. ${ }^{226} \mathrm{Ra}$ activities were determined using the gamma line $186.2 \mathrm{keV}$ after subtraction of the ${ }^{235} \mathrm{U}$ contribution, for which 3 methods were applied:

(1) using the ${ }^{235} \mathrm{U}$ line at $143.8 \mathrm{keV}$ (after interference correction from contributing ${ }^{223} \mathrm{Ra}$, determined by the $144.2,154.2,269.5,323.9$ and $338.3 \mathrm{keV}$ lines),

(2) using $63.3 \mathrm{keV}$ and $92.6 \mathrm{keV}$ line of ${ }^{234} \mathrm{Th}$ and $1001.0 \mathrm{keV}$ line of ${ }^{234 \mathrm{~m}} \mathrm{~Pa}$ for estimation of ${ }^{238} \mathrm{U}$ with activities derived from the natural ${ }^{238} \mathrm{U} /{ }^{235} \mathrm{U}$ activity ratio of 21.7 .

These both methods applied on the metallized plastic foil sealed sample lead to very consistent results with no statistical difference (two sample t-test $(34)=0.46, \mathrm{p}=0.65$ ) (Fig. 1a).

(3) Finally, a combination of methods (1) and (2) was used, applying all 4 mentioned lines for

${ }^{235} \mathrm{U}$ contribution estimation, which resulted in reduction of ${ }^{226} \mathrm{Ra}$ uncertainty by $43 \%$.

While the mean value of ${ }^{226} \mathrm{Ra}$ measured by all 3 methods was close to the reported reference value, the equilibrium value of ${ }^{214} \mathrm{~Pb}$ in the metallized plastic foil sealed sample reached only $88 \%$ that of ${ }^{226} \mathrm{Ra}$. The mechanism of this phenomenon, which has not been explained within this study yet, is speculated to be $\mathrm{Rn}$ diffusion through the foil. The very fine material used for the test is prone to show a high emanation rate. Efficiency problems with daughter product estimation can be excluded, because both daughter products ${ }^{214} \mathrm{~Pb}$ and ${ }^{214} \mathrm{Bi}$ gave consistent results when estimated by lines of wide energy span (between 242 and $1764 \mathrm{keV}$ ). In the parallel experiment using soldered steel container the radioactive equilibrium was reached (Fig. 1 b).

\subsection{Effects of supported ${ }^{210} \mathrm{~Pb}$ underestimation on excess ${ }^{210} \mathrm{~Pb}$ sediment depth profiles}

On 2 theoretical models it is illustrated how systematic underestimation of ${ }^{210} \mathrm{~Pb}_{\text {sup }}$ can affect the resulting sedimentation rate estimation in ${ }^{210} \mathrm{~Pb}_{\mathrm{xs}}$ sediment chronology. The simple example (Profile A) (Fig. 2a) presents a theoretical non-compacted and non-mixed sediment profile with a constant sedimentation rate of $0.25 \mathrm{~cm} \cdot \mathrm{y}^{-1}$. The sampling interval is $1 \mathrm{~cm}$ and the depth of the profile is $30 \mathrm{~cm} .{ }^{210} \mathrm{~Pb}_{\text {sup }}$ being constant $25 \%$ of the total ${ }^{210} \mathrm{~Pb}$ initial activity (top of the profile) is subjected to underestimation by $12 \%$. The value of $25 \%$ for ratio between supported lead and total initial ${ }^{210} \mathrm{~Pb}$ was selected as a "typical value", although based on our experience, it can vary strongly according to local environment, often between 5-50\%. Underestimation of supported lead in this example leads to a constant shift of ${ }^{210} \mathrm{~Pb}_{\mathrm{xs}}$ to greater values.

Another example (Profile B) shows the upper described model modified by adding a random scatter (using normally distributed random number generator) to ${ }^{210} \mathrm{~Pb}_{\text {tot }}$ and ${ }^{210} \mathrm{~Pb}_{\text {sup }}$ data and error bars added (Fig. 2b).

On a real dataset (with scatter caused by counting statistics and other natural causes) excess ${ }^{210} \mathrm{~Pb}$ overestimation can remain unobserved, and could also be attributed to not reaching the "dating horizon". It can possibly be detected by careful examination and finding regular patterns in the residuals plot (after 

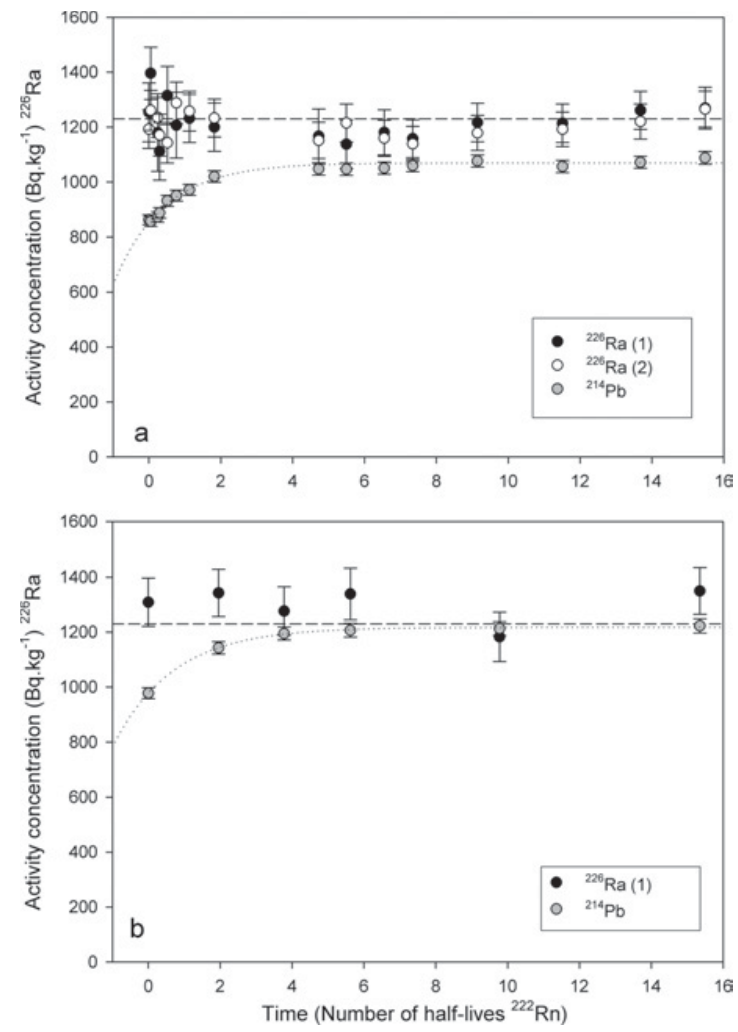

Figure 1. Establishing of radioactive equilibrium in test sample RV VII-2006 within the time interval of approximately 8 weeks for (a) a plastic dish sealed in a metallized plastic foil and (b) a soldered steel container. In the first case, the ${ }^{214} \mathrm{~Pb}$ values reached only $88 \%$ of that of parent ${ }^{226} \mathrm{Ra}$, which was determined by 2 different methods (1) and (2) listed in chapter 4.1. In the steel container the radioactive equilibrium was reached. The dashed line indicates the reference value. The error bars for all data are 1 standard deviation (they include counting statistics and calibration of the measuring device).

fitting) (Fig. 2a), but this effect is not obvious in naturally scattered datasets (Fig. 2b). The described effect will be strongest in environments with higher proportion of supported ${ }^{210} \mathrm{~Pb}$. Systematic error in ${ }^{210} \mathrm{~Pb}_{\text {sup }}$ estimation can therefore have consequences for ${ }^{210} \mathrm{~Pb}_{\mathrm{xs}}$ derived chronologies leading to systematic underestimation of ages.

\subsection{Possible consequences of supported ${ }^{210} \mathrm{~Pb}$ underestimation for chronology}

Two most commonly used chronology models were applied to the upper described 2 theoretical profiles A and B: Constant initial concentration (CIC) model [10] and Constant rate of supply (CRS) model [11].

In the first case (CIC model), ${ }^{210} \mathrm{~Pb}_{\mathrm{xs}}$ profiles were fitted by a simple 2 parameter exponential function using least square algorithm. Based on resulting parameters, sedimentation rates were calculated. The resulting sedimentation rates are $0.284 \pm 0.004 \mathrm{~cm} \cdot \mathrm{y}^{-1}$ for Profile A and $0.280 \pm$ $0.026 \mathrm{~cm} \cdot \mathrm{y}^{-1}$ for Profile B. Sedimentation rates were thus overestimated by over $13 \%$.

For comparison, ${ }^{210} \mathrm{~Pb}_{\mathrm{xs}}$ profiles were used for calculation of ages according to CRS chronology model, which in case of non-scattered Profile A led to even more serious age underestimation than CIC model. Graphical depth/age relationship for both CIC and CRS models for Profiles A and B are presented in Fig. 3. 
(a)
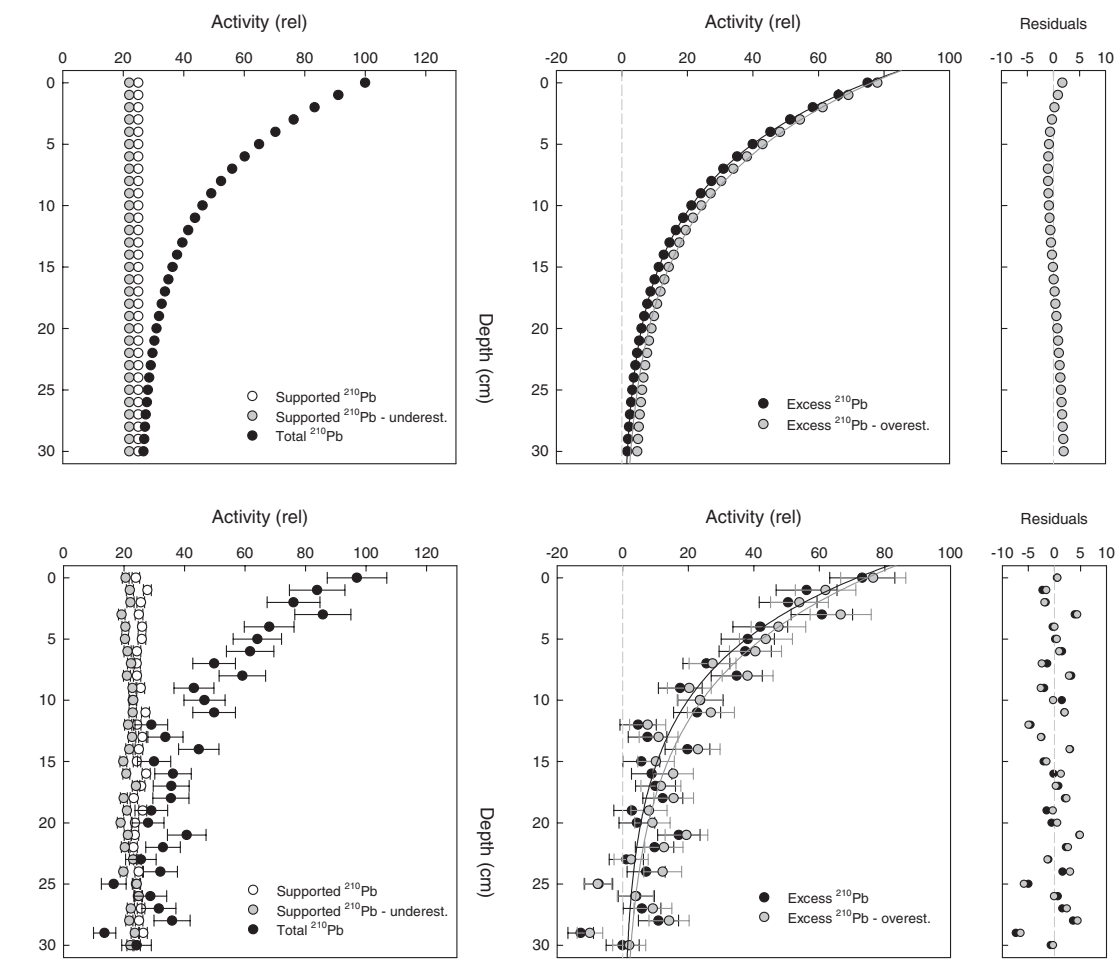

(b)

Figure 2. Theoretical ${ }^{210} \mathrm{~Pb}$ sediment depth profiles described in chapter 4.2.: (a) a simple profile (Profile A) and (b) a profile with a random scatter (Profile B). For both profiles, in the left figures, ${ }^{210} \mathrm{~Pb}_{\text {tot }}$ and both correct and systematically underestimated ${ }^{210} \mathrm{~Pb}_{\text {sup }}$ are depicted. In the central figures, the correct and overestimated ${ }^{210} \mathrm{~Pb}_{\mathrm{xs}}$ (calculated as ${ }^{210} \mathrm{~Pb}_{\text {tot }}{ }^{210} \mathrm{~Pb}_{\text {sup }}$ ), together with simple 2 parameter exponential fits, using least square algorithm, are plotted. In the right figures, residuals to the fits are shown.

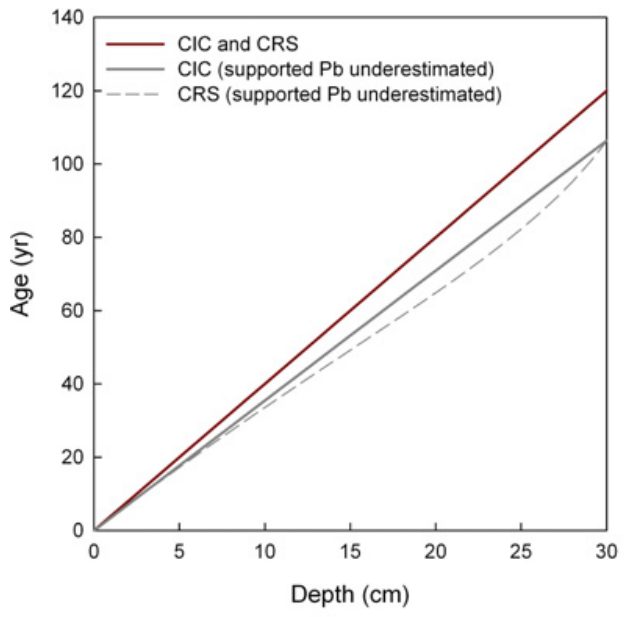

(a)

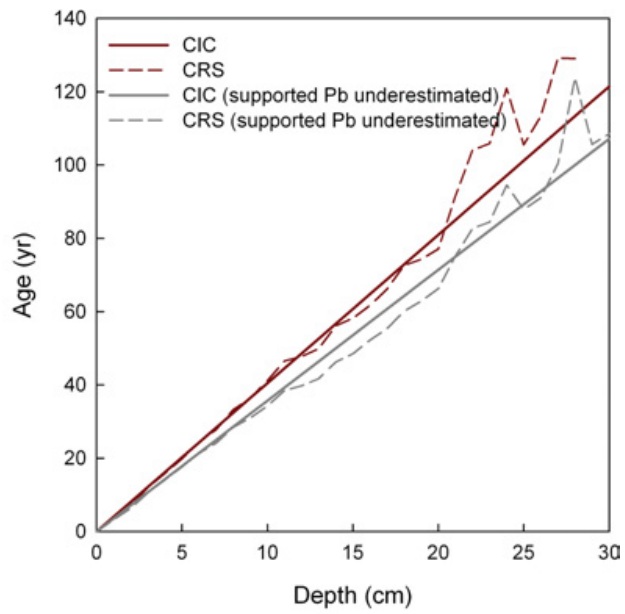

(b)

Figure 3. Chronologies derived from the 2 theoretical profiles: (a) Profile A and (b) scattered Profile B. For both cases chronologies were derived by both CIC and CRS models using both correct and overestimated ${ }^{210} \mathrm{~Pb}_{x s}$ profiles. 


\subsection{Discussion}

A method for testing and correcting possible underestimation of ${ }^{210} \mathrm{~Pb}_{\text {sup }}$ in sediment profiles measured by gamma-spectroscopy is currently being developed. In case of supported lead underestimation caused by partial Rn escape from the measurement containers, corrections can be employed.

\section{CONCLUSIONS}

It was shown that although samples for ${ }^{226} \mathrm{Ra}$ analysis are carefully sealed in presumably gas tight foils, especially in very fine grained samples the radioactive equilibrium required for ${ }^{226} \mathrm{Ra}$ estimation via daughter products might not be reached.

This can theoretically have consequences also for supported ${ }^{210} \mathrm{~Pb}$ estimation via the ${ }^{226} \mathrm{Ra}$ daughter products. A systematic underestimation of ${ }^{210} \mathrm{~Pb}_{\text {sup }}$ can result in systematic underestimation in ${ }^{210} \mathrm{~Pb}_{\mathrm{xs}}$ derived ages, as it was presented on theoretical examples.

\section{References}

[1] Appleby P.G., in: Last, W.M., Smol, J.P. (Eds.), Tracking Environmental Change Using Lake Sediments. Volume 1: Basin Analysis, Coring, and Chronological Techniques (Kluwer Academic Publishers, Dordrecht, The Netherlands, 2001), pp. 171-203.

[2] Zaborska A., Carroll J., Papucci C. and Pempkowiak J., J. Environ. Radioactiv. 93 (2007) 38-50.

[3] Moser R.N., J. Radioanal. Nucl. Ch. 173 (1993) 283-292.

[4] Villa M., Moreno H.P. and Manjón G., Radiat. Meas. 39 (2005) 543 - 550.

[5] Schkade U.K., Arnold D., Döring J., Hartmann M. and Wershofen H., Gammaspectromectric determination of specific activity of natural Radionuclides in environmental samples. 7th Intercomparison "Soil 2006". (Tech. Rep. BfS-SCHR-41/07, German Federal Office for Radiation Protection, Berlin, Germany, 2007) (In German).

[6] Stoulos S., Manolopoulou M. and Papastefanou C., Appl. Radiat. Isotopes 60 (2004) 49-54.

[7] Dowdall M., Selnaes Ø. G., Gwynn J.P. and Davids C., J. Radioanal. Nucl. Ch. 261 (2004) 513-521.

[8] Justo J., Evangelista H. and Paschoa A.S., J. Radioanal. Nucl. Ch. 269 (2006) 733-737.

[9] Bronson F.L., J. Radioanal. Nucl. Ch. 255 (2003) 137-141.

[10] Robbins J.A., in: Nriago J.P. (Ed.), The biogeochemistry of lead (Elsevier, Amsterdam, 1978).

[11] Appleby P.G. and Oldfield F, Catena 5 (1978) 1-8. 